\title{
Basic hope and posttraumatic growth in people with traumatic paraplegia - the mediating effect of acceptance of disability
}

\author{
Stanisława Byra ${ }^{1}$
}

Received: 25 January 2018 / Revised: 14 September 2018 / Accepted: 17 September 2018 / Published online: 29 October 2018

(c) International Spinal Cord Society 2018

\begin{abstract}
Study design Cross-sectional study.

Objectives Investigating the correlations between basic hope, acceptance of disability, and posttraumatic growth (PTG) in people with traumatic paraplegia, exploring the mediating effect of acceptance of disability.

Setting Community-dwelling people with traumatic paraplegia in Poland.

Methods Data were obtained from 281 individuals with paraplegia. The set of questionnaires included: The Posttraumatic Growth Inventory (PTGI); Basic Hope Inventory (BHI); and The Multidimensional Acceptance of Loss Scale. Four dimensions of disability acceptance were measured: subordinating physique relative to other values, enlarging the scope of values, transforming comparative-status values into asset values, and containing the effects of disability. Mediation was tested with the Baron and Kenny's approach.

Results A positive and statistically significant correlation between basic hope, acceptance of disability, and posttraumatic growth was found. Using a hierarchical regression analysis, a mediating effect of acceptance of disability was found for explaining the relationship between basic hope and posttraumatic growth in people with paraplegia. Only two dimensions of disability acceptance, subordinating physique relative to other values and transforming comparative-status values into asset values, were found to play a mediating role.

Conclusion Beliefs about the world and the transformation of values that constitute acceptance of disability are important for explaining PTG in people with paraplegia. Correlations between these variables are complex. The correlation between basic hope and posttraumatic growth in individuals with paraplegia may be understood better by taking into account the mediating role of acceptance of disability.
\end{abstract}

\section{Introduction}

Spinal cord injury (SCI) may lead to changes in both physical and psychosocial aspects of the lives of the people involved [1]. In recent years, the onset of SCI is seen more often as a critical life event that triggers positive changes, and this perspective also is confirmed by research [2-7]. Still, the positive changes and their determinants have not been well identified and explained yet in individuals with SCI. Posttraumatic growth (PTG) is the theoretical concept

Stanisława Byra

stanislawa.byra@poczta.umcs.lublin.pl

1 Faculty of Education and Psychology, Institute of Pedagogy, Maria Curie-Skłodowska University, Lublin, Poland, Narutowicza 12, 20-004 Lublin, Poland commonly used to describe these positive changes. It is conceptualized as a multidimensional construct, including changes in beliefs, behaviors, goals, and identity. According to Tedeschi and Calhoun, PTG is a positive change that occurs as a result of successful coping with the aftermath of traumatic events [8]. PTG tends to be reported in five major domains: improved interpersonal relationships, a greater sense of personal strength, new opportunities, greater appreciation for life, and spiritual growth [9]. The previous studies conducted with persons with SCI indicate relationships of PTG i.e., with coping [7, 10, 11], basic hope [11], depression [2,3], sex, age, education, time since injury [3], and meaningful engagement in activities [6]. However, these studies have not sufficiently examined the role of beliefs in PTG.

According to Tedeschi and Calhoun's theory of PTG, the appearance of positive changes after trauma requires significant transformations in earlier beliefs about the world, 
oneself, possessed capabilities, the future, as well as the place of the traumatic event in the overall perception of one's life $[8,12]$. Research has shown the significant role of beliefs constituting basic hope for PTG among individuals with SCI [11]. Basic hope is understood as a person's generalized and complex beliefs of about the higher order and meaningfulness of the surrounding world and its general positivity toward people [13]. Basic hope correlates positively with PTG in people with long-term SCI [11] and in people who had the injury at least 2 years before study [14]. Former research showed a significant but not very high contribution of basic hope to explain the intensity of PTG in people with SCI. These results, as well as available literature on the adaptation of people after acquisition of SCI $[15,16]$, suggest that generalized beliefs about the world are not the only ones important for the adaptive effects and the experienced positive changes. Disability acceptance related to the perception of the consequences of limitations plays a special role here as well. The most popular understanding of this construct, based on the views of B. Wright, stresses the transformation of the value system necessary after the acquisition of permanent disability to meet the demands imposed by it. Acceptance of disability means that disability becomes incorporated into the person's self-concept $[17,18]$ which, as indicated by previous research, has numerous benefits for the psychosocial functioning of persons with SCI [16, 19-21]. Transformations in the values constituting acceptance of disability also were found to be significant for PTG in persons with acquired physical disability, including SCI [22].

Both phenomena of accepting disability and PTG are connected with experiencing a serious life-changing event, including the acquisition of SCI. The PTG construct is significantly broader and refers to the perception of positive changes in various areas of life that are associated, among others, with improved interpersonal relationships, a greater sense of personal strength, new opportunities, greater appreciation for life, and spiritual growth [23]. Acceptance of disability refers to changes/shifts in the system of values allowing individuals to perceive their disability as neither devaluing nor minimizing their maintained abilities [17].

The purpose of this study was to investigate the correlation between basic hope, acceptance of disability, and PTG in people with traumatic paraplegia. Based on the available theoretical and empirical literatures, the hypothesis is that acceptance of disability will mediate the relationship between basic hope and posttraumatic growth in people with SCI. Disability acceptance is seen as a mediator on the basis of the PTG theory. The acquisition of SCI is a seismic event that forces changes in basic beliefs about the world and oneself $[8,12]$. Therefore, the PTG experience requires the individual to rebuild these belief patterns and incorporate the acquired disability into the self-concept
[24]. Transforming the system of values that make up acceptance of disability requires a kind of cognitive processing that may be necessary for the occurrence of PTG. This assumption is made with the author's full awareness that it is very difficult to statistically test causal relationships in a cross-sectional design.

\section{Methods}

\section{Participants}

Study participants included 304 individuals with paraplegia, 281 of whom qualified for the final data analysis. Twentythree sets of questionnaires were rejected due to missing data. Inclusion criteria included the following: (1) being 18 years of age or older; (2) having a traumatic injury; and (3) being involved professionally and/or socially (in associations, foundations, cultural, and community centers). Individuals with diagnosed cognitive impairments or communication disorders (based on their medical record and reports from their rehabilitation specialists and psychologists) were excluded from the study. The respondents were contacted by rehabilitation specialists and psychologists working in associations and foundations, social welfare centers and rehabilitation centers for people with physical disabilities, including SCI. Socio-demographic variables and variables related to disability are presented in Table 1.

\section{Materials}

Data were collected using the following instruments:

Polish version of The Post-Traumatic Growth Inventory (PTGI- RG. Tedeschi, LG. Calhoun). The PTGI contains 21 items rated on a six-point scale, from 0 - I did not experience this change as a result of my crisis, to 5- I experienced this change to a very great degree as a result of my crisis [25]. Polish adaptation of the instrument was prepared, including translation and retranslation of the items. Confirmatory factor analysis performed by N. Ogińska-Bulik and Z. Juczyński [25] provided grounds for selecting a fourfactor structure. The total score of the PTGI is the sum of the results obtained in the four subscales and ranges from 0 to 105. A higher the score indicates greater PTG. Satisfactory indicators of reliability and validity of the Polish version of the PTGI were obtained. Cronbach's alpha for the PTGI Total was reported as 0.93 [25] (0.92 in the present sample).

The Basic Hope Inventory (BHI) by Trzebiński and Zięba contains 12 statements evaluated by respondents on a fiveitem scale. It is used to determine the general level of basic hope manifested in personal beliefs about the world, its order, meaning, and positive nature. Psychometric 
Table 1 Participant Characteristics

\begin{tabular}{ll}
\hline Characteristics & Descriptor, $n(\%)$ \\
\hline Sex & $193(69)$ \\
Men & $88(31)$ \\
Women & \\
Place of residence & $219(78)$ \\
City & $62(22)$ \\
Rural areas & \\
Marital status & $115(41)$ \\
Married & $84(30)$ \\
Single & $45(16)$ \\
Divorced & $27(10)$ \\
Separated & $7(3)$ \\
Widowed & \\
Education & $31(11)$ \\
Primary & $84(30)$ \\
Vocational & $112(40)$ \\
Secondary & $8(3)$ \\
Incomplete higher & $46(16)$ \\
Higher & \\
Descriptor M (SD) & $45.07(12.67)$ \\
Age & $28.27(12.63)$ \\
Age at the time of injury & $16.27(8.86)$ \\
Duration of disability &
\end{tabular}

properties of the instrument are satisfactory: Cronbach's alpha -0.70 and Pearson's $r=0.62$ [26]. In several studies, Cronbach's alpha was 0.82 [13].

The Multidimensional Acceptance of Loss Scale (Polish Version) (J. M. Ferrin, F. Chan, J. Chronister, Ch-I. Chiu) [16]. Polish adaptation of the instrument was prepared, including translation and retranslation of the items. Satisfactory indicators of reliability and validity of the Polish version of this instrument were obtained. This is a 41-item instrument that contains four components of disability acceptance: (a) A-I: subordinating physique relative to other values (e.g., "I understand I have limitations, but I can achieve a lot in my daily tasks") - Cronbach's $\alpha=0.89$; (b) A-II: enlarging the scope of values (e.g., "It is difficult for me to find other ways of achieving my life goals") - Cronbach's $\alpha=0.88$; (c) A-III: transforming comparative-status values into asset values (e.g., "I perceive only my limitations”) - Cronbach's $\alpha=0.86$; (d) A-IV: containing the effects of disability (e.g., "My disability is only a small part of who I am”) - Cronbach's $\alpha=(0.79)$ [27].

\section{Procedures}

The data were collected from members of associations, foundations, social welfare centers, and rehabilitation centers where people with SCI gather. The research was carried out with the help of trained physiotherapists, psychologists, or pedagogues employed in these facilities. With their input, persons who met the screener criteria were selected. The respondents filled out the questionnaires in the facility to which they belonged. Encoded data were stored in accordance with valid personal data protection regulations.

I certify that all applicable institutional and governmental regulations concerning the ethical use of human volunteers were followed during the course of this research.

\section{Data analysis}

Data were analyzed using SPSS. First, descriptive statistics and coefficients of correlations were prepared for the analyzed variables. To test the hypothesis that acceptance of disability mediates the relationship between basic hope and posttraumatic growth, the Baron and Kenny [28] approach was used. It assumes that testing the mediating effect requires investigating other linkages: (1) an independent variable with a dependent variable (path C); (2) an independent variable with a mediator (path $\mathrm{A}$ ) and a mediator with a dependent variable (path B); (3) an independent variable with a dependent variable, when both the independent variable and the mediator are included in the model (path C') [28]. In the suggested model, basic hope is the independent variable, posttraumatic growth is a dependent variable, and acceptance of disability is a mediator. To study these correlations, a series of regression analyzes were performed.

In this study, the mediating effect results from the comparison of the direct relationship between the independent and dependent variable with the relationship of these two variables when a mediator is added to the model. The mediating effect is significant when the influence of an independent variable on a dependent variable decreases after the mediator is introduced to the model (partial mediation) or becomes irrelevant (total mediation). It assumes a significant relationship in path A and path $\mathrm{B}$. The Sobel test was used to determine if the indirect effect of the independent variable on the dependent variable via the mediator is significant.

\section{Results}

Table 2 presents correlation coefficients between basic hope, posttraumatic growth, and acceptance of disability (and dimensions thereof).

As shown in Table 2, there is a statistically significant, positive correlation between all the variables. They are diverse in terms of the strength of the correlations. A strong 
Table 2 Means, standard deviations and correlations (Pearson's $r$ ) between the analyzed variables

\begin{tabular}{|c|c|c|c|c|c|c|c|c|}
\hline Variables & M & $\mathrm{SD}$ & 1 & 2 & 3 & 4 & 5 & 6 \\
\hline 1.Basic hope $(\mathrm{BH})$ & 25.95 & 4.83 & - & & & & & \\
\hline $\begin{array}{l}\text { 2. Subordinating physique relative to } \\
\text { other values (A-I) }\end{array}$ & 28.73 & 4.92 & $0.40 * * *$ & - & & & & \\
\hline 3. Enlarging the scope of values (A-II) & 26.72 & 5.00 & $0.54 * * *$ & $0.16^{* *}$ & - & & & \\
\hline $\begin{array}{l}\text { 4. Transforming comparative-status } \\
\text { values into asset values (A-III) }\end{array}$ & 28.07 & 4.03 & $0.28 * * *$ & $0.17 * *$ & $0.71 * * *$ & - & & \\
\hline $\begin{array}{l}\text { 5. Containing the effects of disability } \\
\text { (A-IV) }\end{array}$ & 30.07 & 3.86 & $0.22 * * *$ & $0.62 * * *$ & $0.24 * * *$ & $0.24 * * *$ & - & \\
\hline 6.Posttraumatic growth (PTG) & 66.75 & 16.31 & $0.39 * * *$ & $0.54 * * *$ & $0.18 * *$ & $0.16^{* *}$ & $0.40 * * *$ & - \\
\hline
\end{tabular}

basic hope on PTG. Overall, both independent variables (basic hope and disability acceptance) explained $36 \%$ of the variance in PTG (dependent variable). "Subordinating physique relative to other values" (a dimension of disability acceptance) had the greatest contribution to explain the PTG variance in this mediation model. Interestingly, "containing the effects of disability" and "enlarging the scope of values" (dimensions of disability acceptance) do not mediate the relationship between basic hope and posttraumatic growth in the sample of people with SCI.

The indirect effect of the two dimensions of disability acceptance was confirmed by the results of the Sobel's test ("subordinating physique relative to other values" $\mathrm{Z}=4.190, p<0.001$; "enlarging the scope of values": $\mathrm{Z}=1.892, \quad p<0.053$; "transforming comparative-status values into asset values": $\mathrm{Z}=2.673, p<0.007$; "containing the effects of disability": $\mathrm{Z}=1.458, p<0.144$ ).

\section{Discussion}

In this study, the relationship between basic hope and PTG, as well as the mediating effect of disability acceptance on this relationship, was investigated. Similar to the results of previous studies [11, 14], basic hope correlated positively with posttraumatic growth in people with SCI. In this study, positive correlations also were found between basic hope and all dimensions of the acceptance of disability, as well as between the acceptance of disability and PTG. The effect of mediating disability acceptance in explaining the variance of PTG in people with SCI is supported. In other words, increased levels of basic hope were related to increased levels of disability acceptance, which, in turn, led to increased levels of PTG.

Higher basic hope can facilitate transformations in the assessment of one's characteristics and related developmental possibilities. It may change how one perceives values and goals, which were omitted earlier or considered to be less valuable and satisfactory [13]. They also can facilitate transformations in the criteria for assessing oneself 
Fig. 1 Path models of the relations between basic hope, acceptance of disability, and posttraumatic growth. Note: Path A: the relationship between basic hope (independent variable) and acceptance of disability (mediator): Path B: the relationship between acceptance of disability (mediator) and PTG (dependent variable): Path $\mathrm{C}$ : direct relationship between basic hope and posttraumatic growth; Path C': basic hope is associated with PTG, when the mediator is included in the model; A-I: subordinating physique relative to other values; A-II: enlarging the scope of values; A-III: transforming comparative-status values into asset values; A-IV: containing the effects of disability

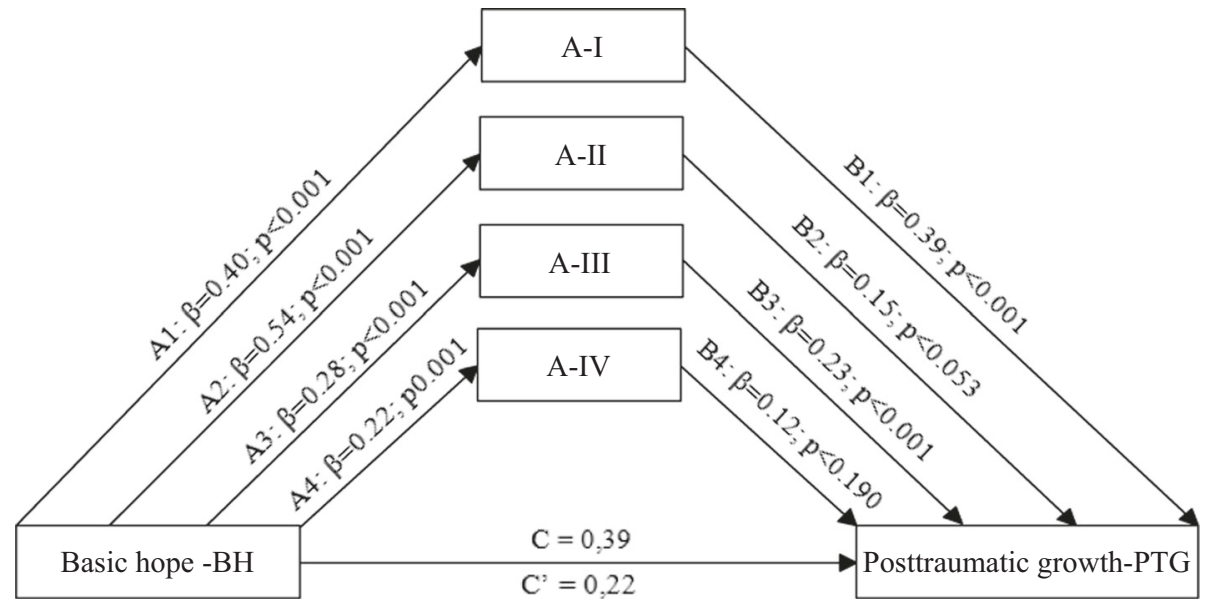

Note: Path A - the relationship between basic hope (independent variable) and acceptance of disability (mediator): Path B - the relationship between acceptance of disability (mediator) and PTG (dependent variable): Path $\mathrm{C}$ - direct relationship between basic hope and posttraumatic growth; Path $\mathrm{C}^{\prime}$ - basic hope is associated with PTG, when the mediator is included in the model; A-I: Subordinating physique relative to other values; AII: Enlarging the scope of values; A-III: Transforming comparative-status values into asset values; A-IV: Containing the effects of disability. and one's own abilities [18]. These results largely are consistent with the results of other studies with people with SCI, indicating the predictive functions of basic hope for explaining the variability of the cognitive dimension of disability acceptance [29], understood in accordance with the assumptions of Livneh and Antonak [30]. In the studies of Livneh and Martz [15], hope-understood as individuals' goal-directed thinking in terms of agency and pathways-correlated positively with the indicator of psychosocial adaptation: acknowledgment (cognitive dimension of acceptance), which refers to efforts to find new meanings and social activity after the acquisition of SCI.

The significance of acceptance of disability in explaining the variability of PTG established in this study is partially supported by other studies. For example, Groomes and Leahy [21] found that individuals who experience a higher level of acceptance of disability are more likely to have positive perspectives on their situation related to disability. At the same time, the results of the presented research indicate the indirect role of acceptance of disability. Interestingly, no mediation effect was found for the dimension containing the effects of disability and enlarging the scope of values. This means that acceptance expressed in containing the effects of disability and enlarging the scope of values is positively correlated with basic hope, but at the same time it is not statistically significant in explaining the relationship between basic hope and PTG in the group of people with SCI. This study has shown that other types of transformations in values, creating dimensions of acceptance of disability, can play a greater role in explaining more PTG changes in people with SCI. The acceptance of disability dimensions: subordinating physique relative to other values and transforming comparative-status values into asset values are treated as conditions for the process of cognitive reorganization aimed at integrating acquired disability into the overall image of oneself and building a new identity [18]. This cognitive reorganization may be conducive to further transformations leading to the occurrence of PTG in people with SCI.

The results of this study indicating that changes in values in disability acceptance may play different roles in the psychological consequences of acquiring SCI are consistent with the results obtained by Ch. P. Lin and co-researchers [20], who suggested that transforming values can provide an impulse for better psychosocial outcomes and experiencing a higher level of life satisfaction by persons with disabilities. Importantly, in their research the dimension of acceptance: containing the effects of disability, also was not significantly related to positive experiences in people with SCI, including life satisfaction. The readiness to broaden one's values and to reduce the emphasis on physicality as a feature that is significantly evaluative contributes to the appreciation of other qualities and abilities. Accepting oneself as a valuable person, whose physicality is not devalued, can create the foundation for PTG. Similarly, the other changes of values in disability acceptance, e.g., transforming comparative-status values into asset values, may facilitate a positive reframing of disability and may "free people to act in ways befitting their own characteristics rather than those of an idolized normal standard" [17, p.183]. 
In contrast to earlier studies on PTG with people with SCI, this is one of the first studies to demonstrate that acceptance of disability mediates the relationship between basic hope and PTG. The results of this study provide interesting information that may be useful in explaining PTG in people with SCI. Nevertheless, this study contains some limitations. First, the survey was cross-sectional, which makes it impossible to set directional hypotheses and explain cause-effect relationships. Longitudinal research would be more adequate to explain the relationship between basic hope, the acceptance of disability, and PTG in people with SCI. Second, the group of participants is not representative. Intentionally, only the people with paraplegia who were active in various spheres of life were included in the research, since they were assumed to have a greater chance of experiencing PTG. Future studies could improve on the current study by utilizing a more representative sample and a longitudinal study design. This is all the more important because this study takes into account both the identification of the positive changes of PTG and the beneficial, adaptive changes in values that are related to acceptance of disability, and these phenomena, PTG, basic hope and disability acceptance, are dynamic and can change over time. Third, additional variables that may be important for the relationship between basic hope, acceptance of disability, and PTG in people with SCI were not controlled in this study. Future studies should include variables, such as age of SCI onset, the level and completeness of the SCI, appraisal of disability or stress level, and sociodemographic data (e.g., socio-economic status and social support).

Despite these limitations, the current findings have theoretical and clinical implications. They support the importance of accepting disability as a possible mediator of the relationship between basic hope and PTG in individuals with SCI. Thus, they broaden our understanding of the factors significant for the occurrence of PTG in this group of people with disabilities. These findings may be used to aid clinical interventions in supporting people with SCI in their efforts to make transformations in their values that constitute the acceptance of disability, which may be conducive not only to achieving successful adaptation effects, but also to experiencing PTG. Useful therapeutic interventions therefore should be oriented toward improving acceptance of disability (including making necessary changes in the value system) and strengthening hope and basic hope. Activities which support PTG, such as seeking and finding the meaning of one's disability, expanding values, developing achievable goals, creating ways to reach them, and discovering and developing resources will be important [31, 32]. In turn, the following interventional approaches indicated in the literature may help in promoting PTG and maintaining positive changes: (a) written or spoken self-expression/disclosure; (b) cognitive-behavioral therapies; (c) novel psychosocial interventions directly promoting growth. Cognitive-behavioral interventions, such as Transforming Lives Through Resilience Education (TLTRE), which aims to promote growth through psychoeducation, cognitive restructuring, personal responsibility, and social support are also useful [33]. Research corroborates the effectiveness of cognitive behavioral therapy for psychosocial issues related to postspinal cord injury [34].

\section{Compliance with ethical standards}

Conflict of interest The author declares that she has no conflict of interest.

\section{References}

1. van Leeuwen CMC, Kraaijeveld S, Lindeman E, Post MWM. Associations between psychological factors and quality of life ratings in persons with spinal cord injury: a systematic review. Spinal Cord. 2012;50:174-87.

2. Kunz S, Joseph S, Geyh S, Peter C. Posttraumatic growth and adjustment to spinal cord injury: moderated by posttraumatic depreciation? Psychol Trauma. 2017;9:434-44.

3. Kalpakjian CZ, McCullumsmith CB, Fann JR, Richards JS, Stoelb $\mathrm{BL}$, Heinemann AW, et al. Post-traumatic growth following spinal cord injury. J Spinal Cord Med. 2014;37:218-25.

4. Kennedy P, Lude P, Elfström ML, Cox A. Perceptions of gain following spinal cord injury: a qualitative analysis. Top Spinal Cord Inj Rehabil. 2013;19:202-10.

5. Weitzner E, Surca S, Wiese S, Dion A, Roussos Z, Renwick R, et al. Getting on with life: positive experiences of living with a spinal cord injury. Qual Health Res. 2011;21:1455-68.

6. Chun S, Lee Y. The experience of posttraumatic growth for people with spinal cord injury. Qual Health Res. 2008;18:877-90.

7. Pollard C, Kennedy P. A longitudinal analysis of emotional impact, coping strategies and post-traumatic psychological growth following spinal cord injury: A 10-year review. Br J Health Psychol. 2007;12:347-62.

8. Tedeschi RG, Calhoun LG. Posttraumatic growth: conceptual foundations and empirical evidence. Psychol Inq. 2004;15:1-8.

9. Morris BA, Shakespeare-Finch J, Rieck M, Newbery J. Multidimensional nature of posttraumatic growth in an Australian population. J Trauma Stress. 2005;18:575-85.

10. January AM, Zebracki K, Chlan KM, Vogel LC. Understanding post-traumatic growth following pediatric-onset spinal cord injury: the critical role of coping strategies for facilitating positive psychological outcomes. Dev Med Child Neurol. 2015;57:1143-51.

11. Byra S. Posttraumatic growth in people with traumatic long-term spinal cord injury: predictive role of basic hope and coping. Spinal Cord. 2016;54:278-82.

12. Linley PA, Joseph S. Positive change following trauma and adversity: a review. J Trauma Stress. 2004;17:11-21.

13. Trzebiński J, Zięba M. Basic hope as a world-view: an outline of a concept. Pol Psychol Bull. 2004;35:173-82.

14. Zięba M, Czarnecka-van Luijken J, Wawrzyniak M. Nadzieja podstawowa i wzrost potraumatyczny (basic hope and posttraumatic growth). Studia Psychologiczne (Psychological. Studies). 2010;49:109-21. 
15. Livneh H, Martz E. Coping strategies and resources as predictors of psychosocial adaptation among people with spinal cord injury. Rehabil Psychol. 2014;59:329-39.

16. Ferrin JM, Chan F, Chronister J, Chiu Ch-Y. Psychometric validation of the multidimensional acceptance of loss scale. Clin Rehabil. 2011;25:166-74.

17. Wright B. Physical disability - A psychosocial approach. New York, USA: Harper \& Row; 1983.

18. Dunn DS. The social psychology of disability. New York, USA: Oxford University Press; 2015.

19. Berry JW, Elliott TR, Rivera P. Resilient, undercontrolled, and overcontrolled personality prototypes among persons with spinal cord injury. J Pers Assess. 2007;89:292-302.

20. Lin Ch-P, Wang Ch-Ch, Fujikawa M, Brooks J, Eastvold-Walton $\mathrm{L}$, Maxwell K, et al. Psychometric validation of the brief adaptation to disability scale-revised for persons with spinal cord injury in Taiwan. Rehabil Res, Policy, Educ. 2013;27:223-31.

21. Groomes DAG, Leahy MJ. The relationships among the stress appraisal process, coping disposition, and level of acceptance of disability. Rehabil Couns Bull. 2002;46:15-24.

22. Byra S. Predyktory pozytywnych zmian u osób z nabytą niepełnosprawnością ruchową (predictors of positive change in individuals with acquired physical disability). Niepełnosprawność Dyskursy Pedagog Spec (Disabil Discourses Spec Educ). 2015;18:18-37.

23. Taku K, Cann A, Calhoun LG, Tedeschi RG. The factor structure of the posttraumatic growth inventory: a comparison of five models using confirmatory factor analysis. J Trauma Stress. 2008;21:158-64.

24. Janoff-Bulman R. Posttraumatic growth: three explanatory models. Psychol Inq. 2004;15:30-34.

25. Ogińska-Bulik N, Juczyński Z. Rozwój potraumatyczny - charakterystyka i pomiar. (posttraumatic growth-characteristics and measurement). Psychiatr (Psychiatry). 2010;4:129-42.
26. Trzebiński J, Zięba MNadzieja. strata i rozwój. (hope, loss and development). Psychol Jakości Życia (Qual Life Psychol). 2003;1:5-33.

27. Byra S. Wielowymiarowa Skala Akceptacji Utraty Sprawności (WSAUS)—polska adaptacja Multidimensional Acceptance of Loss Scale Jamesa M. Ferrina, Fonga Chana, Julie Chronister i Chung-Yi Chiu. (WSAUS - Polish adaptation of the Multidimensional Acceptance of Loss Scale by James M. Ferrin, Fong Chan, Julie Chronister and Chung-Yi Chiu). Człowiek - Niepetnosprawność - Społeczeństwo (Man-Disability - Society) 2017; 1: 29-50.

28. Baron MR, Kenny DA. The moderator-mediator variable distinction in social psychological research: Conceptual, strategic, and statistical considerations. J Pers Soc Psych. 1986;51:1173-82.

29. Byra S. Przystosowanie do życia z niepetnosprawnościq ruchowa $i$ choroba przewlekta. Struktura i uwarunkowania. (adaptation to life with physical disability and chronic illness. structure and determinants). UMCS: Lublin, Poland, 2012.

30. Livneh H, Antonak RF. Psychosocial adaptation to chronic illness and disability.. MD: Aspen, USA: Gaithersburg; 1997.

31. Dunn DS, Burcaw S. Disability identity: exploring first person accounts of disability experience. Rehabil Psychol. 2013;58:148-57.

32. Snyder CR, Ilardi S, Mitchell ST, Cheavens J. Hope theory: updating a common process for psychological change. In: Snyder $\mathrm{CR}$, Ingram RE, (eds). Handbook of Psychological Change: Psychotherapy Processes and practices for the 21st Century. New York: John Wiley and Sons; 2000. p. 128-53.

33. Roepke AM. Psychosocial interventions and posttraumatic growth: a meta-analysis. J Consult Clin Psychol. 2015;83:129-42.

34. Mechta S, Orenczuk S, Hansen KT, Aubut JA, Hitzig SL, Legassic M, et al. An evidence-based review of the effectiveness of cognitive behavioral therapy for psychosocial issues post-spinal cord injury. Rehabil Psychol. 2011;56:15-25. 